
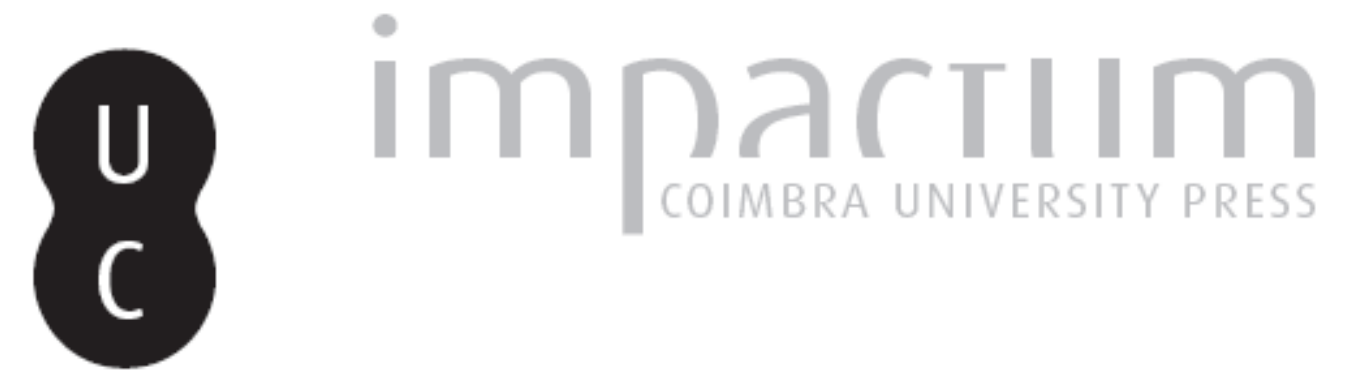

\title{
Entre-laços ou no intestino de um cão
}

Autor(es): $\quad$ Fiorotti, Devair Antônio

Publicado por: Faculdade de Letras da Universidade de Coimbra

URL persistente:

URI:http://hdl.handle.net/10316.2/32765

DOI:

DOI:http://dx.doi.org/10.14195/0870-4112_7_18

Accessed : $\quad$ 26-Apr-2023 08:53:22

A navegação consulta e descarregamento dos títulos inseridos nas Bibliotecas Digitais UC Digitalis, UC Pombalina e UC Impactum, pressupõem a aceitação plena e sem reservas dos Termos e Condições de Uso destas Bibliotecas Digitais, disponíveis em https://digitalis.uc.pt/pt-pt/termos.

Conforme exposto nos referidos Termos e Condições de Uso, o descarregamento de títulos de acesso restrito requer uma licença válida de autorização devendo o utilizador aceder ao(s) documento(s) a partir de um endereço de IP da instituição detentora da supramencionada licença.

Ao utilizador é apenas permitido o descarregamento para uso pessoal, pelo que o emprego do(s) título(s) descarregado(s) para outro fim, designadamente comercial, carece de autorização do respetivo autor ou editor da obra.

Na medida em que todas as obras da UC Digitalis se encontram protegidas pelo Código do Direito de Autor e Direitos Conexos e demais legislação aplicável, toda a cópia, parcial ou total, deste documento, nos casos em que é legalmente admitida, deverá conter ou fazer-se acompanhar por este aviso.

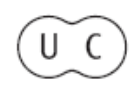




\section{Sociedade em Tumulto}

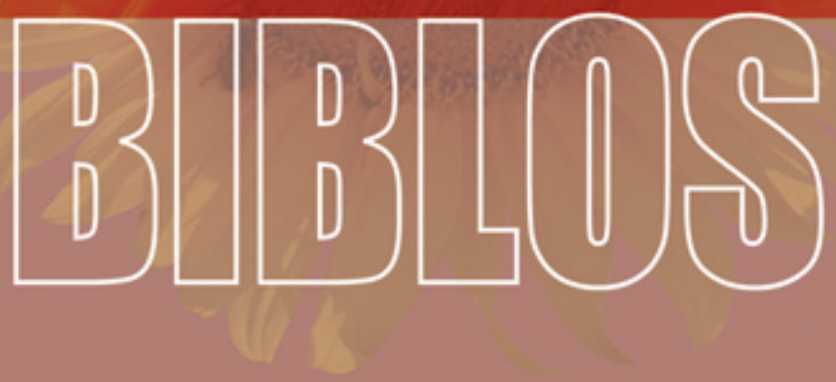

REVISTA DA FACULDADE DE LETRAS

UNIVERSIDADE DE GOIMBRA 
Biblos, n. s. VII (2009) 411-426

Devair Antônio Fiorotti

Universidade Estadual de Roraima

\section{ENTRE-LAÇOS \\ OU \\ NO INTESTINO DE UM CÃO}

\section{Resumo}

O texto analisa comparativamente os narradores-personagens de $A$ hora da estrela e de A paixão segundo G.H., de Clarice Lispector, e de Avalovara, de Osman Lins. Guia-se por certo conflito surgido na narrativa, pelo confronto entre o mundo ficcional e a realidade.

Palavras-chave: narrativa brasileira contemporânea; opressão; realidade $\mathrm{x}$ ficção.

\section{Abstract}

The text comparatively analyzes the narrator-characters of The Hour of the Star and The Passion According to G.H., by Clarice Lispector, and Avalovara, by Osman Lins. It follows the conflict that emerges in the narrative from the confrontation between the fictional world and reality.

Keywords: Brazilian contemporary narrative, oppression, reality vs. fiction.

[Os índios] Andavam já mais mansos e seguros entre nós, do que nós andávamos entre eles.

[...] em maneira que são muito mais nossos amigos que nós seus.

(Fragmentos da carta de Pero Vaz de Caminha)

Diz Guimarães Rosa que: "Ergo: / O livro pode valer pelo muito que nele não deveu caber. / Quod erat demonstrandum." (ROSA, 1969, p. 12). Na frase, criando um neologismo, algo thaumatiza o pesquisador, deixa-o em estado de espanto. Em tom de conclusão, Rosa diz ergo, i. é, diz que, portanto, um livro pode ter um valor por aquilo que nele não coube, "que nele não deveu caber". Nesse contexto, não esqueçamos: a obrigação está ali presente, no dever, no "deveu". 
Quando algo não cabe num livro, está em excesso, dizemos que há um desajuste, uma inadequação. Porém, na estrutura organizacional de Guimarães Rosa, não caber não significa que nele não esteja presente, mas que talvez esteja lá, sobrando. Pode estar lá, no livro, apontando para nós com dedo. Esse apontar com dedo em nosso rosto, principalmente quando não queremos ver para onde aponta o dedo, pode causar desconforto, certo mal-estar, destacadamente causados por aquilo que não deveria estar presente mas que, na obra, presenciase. Talvez, por isso, Guimarães Rosa dirá logo após o fragmento analisado: quod erat demonstrandum, i. é, "porque estava sendo/era demonstrado." Esse não caber não significa que ali não estivessem as informações mas que, para Guimarães Rosa, podem estar sendo demonstradas.

Nessa vereda, Rosa pode estar discutindo a forma como algo é apresentado numa obra: algo pode estar sendo trabalhado no "estar sendo demonstrado"; nas entre linhas; no não caber; numa inadequação entre o dito, o que cabe, e o que também é dito, só que de uma outra forma: a demonstração do dito que não coube. Demonstrar é provar, confirmar; é mostrar a existência de algo. Em Língua Portuguesa, essa palavra traz um recalque: o monstro da demonstração: de (monstra) r; o radical "monstro", daquilo que ao mostrar-se aterroriza, olha-nos de soslaio.

Depois de mais de 500 anos, como denuncia a epígrafe deste trabalho, oriunda do texto tido por alguns como inaugurador da literatura brasileira, as palavras de Vaz de Caminha são sintomáticas de como algo pode estar sendo demonstrado. Dentro da teorização proposta por Mieke Bal, na narrativa de Caminha, estaríamos diante do responsável pela focalização, o focalizor (1997: 104). O focalizador apresenta o ponto do qual os objetos são vistos (Idem). É o ponto em que se encontra Vaz de Caminha que o denuncia: o da coroa portuguesa e seus interesses econômicos, sem importar-se muito pelos habitantes locais, pela amizade que, na fala de Caminha, o outro apresentava ter: os índios andavam mais mansos e seguros entrem nós brancos, do que nós entre eles; eles eram mais nossos amigos, do que nós deles. No texto de Caminha, há outra dimensão do que é dito, alheia aos interesses indígenas, organizada e trazida à tona pelo ponto focalizador da narrativa: o do conquistador. Esse efeito de sentido nos causa incomodo até hoje.

Em análoga situação de focalização, o poeta brasileiro Ferreira Gullar diz em "Não há vagas": 
O preço do feijão

Não cabe no poema. O preço

Do arroz

Não cabe no poema.

Não cabem no poema o gás

A luz o telefone

A sonegação [...]

O funcionário público

Não cabe no poema

Com seu salário de fome

Sua vida fechada

Em arquivos.

[...]. (GULLAR, 1975: 224)

No poema, Gullar diz que muita coisa não caberia no poema. Porém, aquilo que ele diz não caber está sempre presente, mostrando a existência de algo que não caberia, mas que ali está, causando desconforto, demonstrando. Tanto o preço do feijão, do arroz, quanto o salário baixo do funcionário público invadem o texto, apontando para a existência de uma dimensão assombrosa, similar à realidade desconcertante anunciada pelo texto de Caminha. Texto este anunciador (no sentido religioso da palavra) de um extermínio indígena que se estende até nossos dias.

$\mathrm{Na}$ perspectiva do ponto focalizador, persigo aqui algo que está sendo demonstrado na estrutura da construção da narrativa pelo narrador, em sua focalização. Algo que pode confirmar a existência de um mal-estar presente na relação de alguns narradores da literatura contemporânea brasileira com o objeto a ser narrado. Mal-estar, desconforto que penetra a estrutura do romance e que pode estar influenciando na própria concepção do gênero romanesco. Analiso, pelo método comparativo, textos de Osman Lins, principalmente de sua personagem Abel, de Avalovara, com personagens de Clarice Lispector, das obras A hora da estrela e A paixão segundo G.H.

O nível discursivo oriundo de Rosa, que abre meu texto, enveredase por certa dimensão paradoxal. Não a ignoro. Pelo contrário, aceito esse nível e busco instalar-me nele, na busca de deslindar algumas questões referentes à literatura dos autores que serão estudados. Falar 
que algo que não cabe estaria lá demonstrado traz tal dimensão. $\mathrm{O}$ mesmo ocorre quando referir-me, relativo à construção da narrativa, a narrador-personagem ignorando a presença do autor, em detrimento de um posicionamento teórico. Como ensina Stephen, de James Joyce, em A portrait of the artist as a young man, o artista estaria sempre lá. ${ }^{1}$

\section{O direito ao grito, nós homogênio}

Em Hora da estrela, de Clarice Lispector, a narrativa é realizada por um narrador-personagem, Rodrigo S. M. Ele busca narrar a história da datilógrafa Macabéa, uma nordestina no Rio de Janeiro: ali se indo. Rodrigo digladia-se com sua criação, Macabéa. Intrigante é saber que Rodrigo se apresenta como personagem, e mais, ele se vê como uma das personagens mais importantes da obra (LISPECTOR, 1997: 27). Mas ser uma das personagens mais importantes não exime Rodrigo de seu papel, enquanto narrador, de criar e se criar, ao mesmo tempo em que conta a história. Entre o contar a história de Macabéa e o contar-se, nesse imbricado jogo, surgem vestígios da realidade brasileira, surge uma dimensão conflituosa, impostos pela realidade cruel oriunda do objeto a ser narrado: Macabéa.

Talvez Rodrigo, por isso, dirá: "é minha obrigação contar sobre essa moça..." (Idem, sem itálico no original). A palavra "obrigação" denuncia o narrador-personagem. Contar sobre Macabéa não é somente uma opção. Essa palavra modalizadora diz de uma ordem que o narrador não revela qual é. Com ela, simplesmente a determinação está imposta, como um imperativo. Tal imperativo é uma das forças propulsoras da relação conflituosa entre o narrador e sua personagem.

${ }^{1}$ The personality of the artist, at first a cry or cadence or a mood and then a fluid and lambent narrative, finally refines itself out of existence, impersonalizes itself, so to speak. The esthetic image in the dramatic form is life purified in and reprojected from the human imagination. The mystery of esthetic, like of material creation is accomplished. The artist, like the God of creation, remains within or beyond or above handiwork, invisible, refined out of existence, indifferent, paring his fingernails. (1996, p. 244-5, sem destaque no original). Nesse sentido, não ignoro as discussões a respeito da relação entre o autor, o narrador e as personagens. Simplesmente neste trabalho adoto o narrador como construtor da narrativa, já que a estrutura da narrativa e sua relação com a autoria não são o foco de meu texto. Essa relação foi discutida em minha tese de doutorado: A palavra encena: uma discussão da linguagem poética a partir de Manoel de Barros. Universidade de Brasília, UnB, 2006. 
Falando da personagem central de seu livro mais conhecido, Avalovara, livro traduzido para vários idiomas, Osman Lins dirá que "Abel não escreveu Avalovara, ele foi escrito em Avalovara." (LINS, 1979: 177). ${ }^{2}$ Abel, a personagem central e narradora, que também seria um escritor, é palavra. Essa citação de Osman Lins resume a posição em que se encontra o narrador-personagem Rodrigo. Ele é uma personagem-escritor, dentro de uma obra: escritor sim, mas também criação. Noutra instância, escritor escrito numa obra que se sente obrigado a contar algo: a história de uma anti-história, Macabéa.

Na relação que se estabelece entre criador e criação, um desajuste invade e contamina a narrativa, por exemplo, no tom com que o narrador trata o seu objeto a ser narrado, no ponto focalizador em que ele se localiza. "Ela me acusa e o meio de me defender é escrever sobre ela" (LISPECTOR, 1997, p. 31), "estou passando por um pequeno inferno com essa história" (Idem, p. 55), diz Rodrigo. De que Macabéa o acusa? Por que ele tem de se defender da acusação, já que o objeto a ser narrado é "como uma cadela vadia..." (Idem, p. 32)? Por que ele precisa suportar a história de Macabéa? Mas, como ele mesmo diz: "ela me incomoda tanto que fiquei oco" (Idem, p. 41). Destacando uma idéia já apresentada aqui: por que seria uma obrigação para ele narrar a história de Macabéa? Por que esse imperativo?

Rodrigo é invadido pela existência de Macabéa, pela realidade que ela representa. Realidade que se opõe, a priori, à posição em que ele se encontra: o escritor intelectual. E ele pergunta: "mas por que estou me sentindo culpado?" (Idem, p. 38). Rodrigo instaura a narrativa com realidades nas quais ele se posiciona como se delas não pudesse fugir. Dessa organização, surge um incômodo na narrativa, representado pela posição em que o focalizador se localiza. Tal posição, diante do terrível macabeano, passa a interferir na organização do enredo. Com isso, é possível afirmar que, pelo incômodo, o focalizador se focaliza.

Buscando entender por que Rodrigo se sente tão interferido por Macabéa, lembro das lições de Aristóteles. Diz o Estagirita que o espectador da tragédia se sente afetado por aquilo que afeta o herói trágico, pois tal herói seria semelhante ao espectador, semelhante nosso, já que o terror, phóbos, surgiria em relação a "[...] nosso semelhante

${ }^{2}$ Para uma análise aprofundada dessa difícil leitura da literatura brasileira, Avalovara, consultar: DALCASTAGNÈ, Regina. A garganta das coisas. Brasília: Editora Universidade de Brasília: São Paulo: Imprensa Oficial do Estado, 2000. 
[hómoion] desditoso" (ARISTÓTELES, 1951: 88) e a piedade, éleos, seria suscitada diante "de quem é infeliz sem merecer" (Idem).

Mesmo reconhecendo a diferença que há entre a tragédia grega e o romance contemporâneo brasileiro, mesmo reconhecendo a dificuldade de afirmar categoricamente que Macabéa é uma personagem trágica, no sentido grego da palavra, é inegável que sentimos forte incômodo por causa de sua existência, de sua presença no romance: apiedamo-nos por elae, ao mesmo tempo, também nos aterrorizamos por sua existência, pois ela é semelhante a Rodrigo, é semelhante a nós. Somos seres humanos sujeitos a situações análogas, pois o acontecido com Macabéa poderia ter acontecido conosco. Desse caráter homogeneizante da condição humana, não há fuga. Diz Rodrigo assustado: "quando penso que eu podia ter nascido ela - e por que não? - estremeço." (LISPECTOR, 1997, p. 54). Lembro que uma das traduções possíveis para phóbos é "tremor", palavra que possui a base sêmica de "estremecer", palavra usada por Rodrigo para representar seu t(r)emor.

Está em jogo, nas palavras já discutidas de Aristóteles, a identificação com herói. As palavras em grego que apontam para tal identificação são philánthropon e hómoion, que aparecem por duas vezes consecutivas no texto grego (ARISTÓTELES, 1798: v. 53a 1-7). Eudoro de Sousa ${ }^{3}$ traduz philánthropon por "sentimento humano" e, hómoion por "semelhante". Rodrigo está em situação análoga a nós diante de Macabéa, guardadas as devidas restrições. Ele está apiedado e aterrorizado pela existência de Macabéa, seu semelhante, ser humano como ele, sujeito a intempéries semelhantes. Rodrigo está tocado pela possibilidade humana representada por Macabéa: somente a possibilidade de ter nascido ela o faz estremecer. O que liga Rodrigo a Macabéa pode ser entendido, numa perspectiva trágico-aristotélica, como um sentimento humano homogeinizante, de hómoion; como a possibilidade de acometer-nos o acorrido com Macabéa. Isso toca-nos, unindo-nos como representantes de uma mesma estirpe.

Mas num ponto Macabéa se distância de Aristóteles: ela não cometeu nem um erro [hamartían] (ARISTÓTELES, 1951: 88) para despencar da felicidade para a infelicidade. Pela narrativa de Rodrigo, ela nem conheceu a felicidade. Talvez o erro maior dela, já pensamento com o coro de Édipo em Colono, seria ter nascido. Como diz o texto grego: Mê phynai ton apanta nikai logon; to d', epei phanei / Bênai

${ }^{3}$ Helenista já falecido e responsável pela principal tradução d'A poética, de Aristóteles, para o português. Fundou o CEC - Centro de Estudos Clássicos, na UnB. 
keis' opothen per hêkei / Poly deýteron hos takhista. (SÓFOCLES, 1959: v. 1225-27). ${ }^{4}$

Estabelece-se, nesse contexto, umarelaçãode sinonímia e antonímia entre Macabéa e Rodrigo. Numa estrutura sinonímica, Rodrigo é tão humano quanto Macabéa e sujeito a intempéries análogas; noutra, já antonímica e mais superficial, Rodrigo percebe o mundo que os separa: o intelectual-escritor opondo-se a uma existência extremamente rude, arcaica, miserável. Nesse arranjo sinonímico e antonímico, Rodrigo é levado a perceber a opressão social consumindo a existência de Macabéa, obrigando-o a se posicionar em relação ao que vê; enquanto Macabéa, envolvida por tal opressão, pela falta de informação, parece não perceber como ela é fruto de uma desestruturação, de um desarranjo social.

\section{A palavra envenenada}

A personagem-narradora Abel diz que "A palavra sagra os reis, exorciza os possessos, efetiva os encantamentos. Capaz de muitos usos, também é a bala dos desarmados e o bicho que descobre as carcaças podres." (LINS, 1995: 226). A palavra de Rodrigo está em situação análoga à palavra de Abel acima citada, personagem de Avalovara. Ela é o meio em que Rodrigo está envolto, sendo criador e criação, descobridor de carcaças podres e, de repente, se descobrindo como uma carcaça podre. A palavra denuncia o desconforto de Rodrigo diante da carcaça macabeana e, por extensão, o desconforto em que o intelectual se encontra, por causa da opressão social. Tal opressão constrói um ser como Macabéa, semelhante a Rodrigo: algo quase inenarrável, poluidor do narrador e de sua narrativa. A palavra possibilita que Rodrigo desenterre Macabéa, expondo-a ao primeiro plano. A palavra tornase arma denunciadora de uma situação terrível. Macabéa ganha, com sua existência num livro (livro que é um subterfúgio intelectual), voz; ou como diz um dos subtítulos da obra de Lispector, Macabéa ganha Direito ao grito.

Contudo, o grito vem, paradoxalmente, abafado e ampliado. Abafado porque a voz de Macabéa vem filtrada e distorcida, principalmente pela ironia e pela crueldade com que Rodrigo lida com sua criação; ao mesmo

${ }^{4}$ Em uma tradução possível: "melhor [para o homem] seria não ter nascido, já que nasceu, depois de ver a luz, o melhor é voltar, o mais rápido possível, para o lugar de onde veio.’[Minha tradução] 
tempo, a existência de Macabéa se amplia como negação, pois é possível ao leitor perceber a ironia, a crueldade e, destacadamente, o incômodo que a querida Maca, plagiando Rodrigo, causa a esse narrador.

Mas este desconforto não se restringe ao narrador: pela crueldade e ironia dispensadas por Rodrigo à Macabéa, o leitor é levado a vivenciar tal desconforto. Desconforto causado pelo mundo cruel com que essa nordestina digladia-se, enquanto representante de uma nação: a brasileira, e mesmo de uma raça: a humana. Isso é possível principalmente porque, como destaca Aristóteles, nos apiedamos e aterrorizamos com o que vivencia a personagem. Somos afetados, assim como Rodrigo o é.

\title{
Invadido pela opressão
}

\begin{abstract}
Abel diz que
a opressão, fenômeno tendente a legitimar muitos outros males e em geral os mais prósperos, reduz a palavra a uma presa de guerra, parte do território invadido. Lida o escritor, na opressão, com um bem confiscado. (LINS, 1995: 227).
\end{abstract}

Diante da opressão, diz o narrador e escritor Abel, o escritor tem em mãos um bem confiscado, matéria imprópria. A palavra torna-se uma presa de guerra e está sujeita a tal guerra. Avalovara foi escrita em plena ditadura militar brasileira, década de 70 do século passado. Localizada a obra nesse período e recordando as barbáries cometidas pelo regime militar, fica mais fácil entender como a opressão torna-se tema dessa obra e de outras, como demonstra Regina Dalcastagnè no livro $O$ espaço da dor: o regime de 64 no romance brasileiro.

A personagem Rodrigo está em situção análoga a Abel: diante da opressão, de uma guerra social. Uma das questões que Rodrigo expõe é como fugir desta guerra; como isolar a palavra da existência de Macabéas? Macabéa contamina a narrativa de Rodrigo. Incomoda-o. Incrimina-o. Culpa-o pelo estado em que ela se encontra. A voz de Macabéa é seu silêncio angustiante diante do mundo oprimindo-a, sem que ela nem perceba direito tal opressão. A partir das idéias de Abel, a liberdade do escritor seria limitada, pois a realidade invadiria e contaminaria a narrativa, tornando-se parte de sua existência. Hannah Arendt irá dizer que tudo aquilo com o qual os homens entram em contato torna-se uma condição da existência humana (1981, p. 17), 
parte dela. Nesse sentido, fica mais evidente o posicionamento das personagens-escritoras em questão, a relação de pertença e impossibilidade de fugir da realidade social que afeta as personagens-narradoras-escritoras.

Nesse âmbito, Rodrigo chega ao extremo de afirmar, querendo aliviar a diferença social gritante entre ele e Macabéa: "parece-me covarde fuga o fato de eu não a ser." (LISPECTOR, 1997, p. 54). Por mais que ele se angustie, ele nunca a será: não dianta ele não fazer a barba, adquirir olheiras, dormir pouco, vestir-se com roupa velha e rasgada, para se pôr ao nível de sua personagem (Idem, p. 34). O máximo conseguido por ele é provar a existência de Macabéa, pois ele nunca a será. Ela é, como ele mesmo afirma, "uma verdade da qual eu não queria saber."(Idem, p. 55). Contudo, seria possível não saber, sendo ela parte de sua existência humana?

\section{Indiferença ou cumplicidade}

Uma das questões oriundas até o momento das obras analisadas é se seria possível, por parte do escritor, indiferença em relação à opressão seja ela social ou ditatorial. Abel se pergunta a respeito disso:

A indiferença do escritor é adequada à sua presumível elevação de espírito? Para defender a unidade, o nível e a pureza de um projeto criador, mesmo que seja um projeto regulado pela ambição de ampliar a área do visível, tem-se o privilégio da indiferença? Preciso ainda saber se na verdade existe a indiferença: se não é, e só isto, um disfarce da cumplicidade. (LINS, 1995: 306-7)

Abel de Osman Lins, neste trecho, toca em um ponto nevrálgico para escritor moderno: o problema da indiferença do escritor em relação ao mundo ao seu redor. Seria o escritor capaz de tal indiferença? Abel no começo se pergunta sobre a indiferença, mas no final da citação, depois dos dois pontos, a resposta vem com ponto final, aludindo à possibilidade da indiferença ser apenas uma forma de cumplicidade. Em entrevista, Osman Lins diz: "eu aceito a história, e me volto para a história, aceito os meus compromissos diante da história e não quero renunciar a ele." (1979, p. 219). Abel e seu criador pensam de forma parecida: por meio deles, a angústia da realidade invade a obra literária. Tanto um quanto outro, como autores, revelam preocupação diante das mazelas sociais. Realidade que penetra a obra, invadindo-a. 
Ao representar uma realidade da qual não se pode simplesmente se eximir, Macabéa cola em Rodrigo. Ele tenta achar um culpado para tamanho incômodo: "não sei a quem acusar mas deve haver um réu." (LISPECTOR, 1997, p. 55). No contexto, não aparece diretamente um réu, mas Rodrigo se sente culpado (Idem, p. 54). Sente-se culpado, pelo menos, como qualquer ser humano consciente dos problemas relacionados às diferenças sociais. Desta culpa seria possível fugir? Seria possível ser indiferente a ela? Recordemos que ele se sente obrigado a ter Macabéa como sua personagem.

Abel alude à possibilidade de se ser cúmplice dos causadores de opressão, do caos social, quando agimos com indiferença, quando não nos posicionamos diante das questões, diante dos problemas. Penso que é possível Rodrigo se sentir obrigado a lidar com Macabéa, por não querer ser cúmplice dos causadores de realidade tão atroz.

Ainda a respeito da opressão, Abel dirá:

Busco as respostas dentro da noite e é como se estivesse nos intestinos de um cão. A sufocação e a sujeira, por mais que procure defender-me, fazem parte de mim, de nós. Pode o espírito a tudo sobrepor-se? Posso manter-me limpo, não infeccionado, dentro das tripas de um cão? Ouço: 'A indiferença reflete um acordo, tácito e dúbio, com os excrementos'. Não, não serei indiferente. (LINS, 1995: 307)

Abel propõe-se a demonstrar a impossibilidade de ele, escritor, ser indiferente à realidade que o rodeia. A metáfora por ele utilizada é bem sintomática: como o escritor poderia se manter limpo, estando dentro de um mundo contaminado, infeccionado? O cão é mostrado como metáfora do mundo. O escritor não é localizado como coração, nem estando nele. Ele é posto nas tripas, junto aos excrementos, sendo esses excrementos vistos por Abel como a realidade. Dessa localização vem o questionamento: como o escritor poderia se manter indiferente à realidade que o rodeia? Abel, personagem-escritor, declara que não será indiferente. Esse é também o posicionamento de seu criador, Osman Lins:

No momento, vivo dentro de um conflito, não é porque estou naturalmente voltado para o universo, mas continuo ligado de maneira profunda à realidade do meu tempo, ao dia-a-dia, aos acontecimentos diários de meu povo. (1979: 219) 
Assim, autor e criação, Osman Lins e Abel não se propõem a estar indiferentes à realidade que os rodeia. Tal realidade acaba por poluir a obra, contaminando-a. Essa contaminação, lembrando Guimarães Rosa, é o que não cabe, o que sobra, quod erat demonstrandum, que estava sendo demonstrado. Os narradores estudados até esse ponto localizam suas obras a partir desse ponto de focalização.

Convém lembrar que a história de Macabéa surge de um contato com a realidade. Diz Rodrigo que pegou o sentimento de perdição da nordestina, de relance, numa rua do Rio de Janeiro (LISPECTOR, 1997, p. 26). Logo, da realidade vem o mote para construção da história. Desse mote, o narrador envereda-se por um campo movediço de angústias, aflições. Literalmente, ele se enreda em sua teia ao tecer o tecido ao qual teceria Macabéa.

\section{O grafismo de Janair}

Outra obra de Clarice Lispector corrobora para entendermos melhor a relação conflituosa entre realidades distintas, que acaba gerando opressão. Em Apaixão segundo G.H., obra com enorme apelo metafísico, publicada pela primeira vez em 1977, a priori, tem-se somente a voz de G.H., uma personagem-narradora. G.H. busca respostas a respeito de sua existência em quase toda obra. Porém, quando demitiu a empregada e resolveu limpar o quarto dela (da empregada), dele vem uma voz abafada: desenhos quase rupestres feitos a carvão na parede. Diz G.H.: "e foi numa das paredes que num movimento de surpresa e recuo vi o inesperado mural" (LISPECTOR, 1998, p. 38). A voz da empregada dentro da obra surge inesperadamente e demarca sua existência na casa da intelectual escultora, G.H.. E ela diz: "o desenho não era um ornamento: era uma escrita" (Idem, p. 40). G.H. tenta lembrar do rosto da empregada e tem dificuldade (Idem). Acaba lembrando de seu nome, Janair (Idem). Do desenho na parede vem a voz interpretável por G.H., ela se sente incomodada: "meu mal-estar era de algum modo divertido: é que nunca antes me ocorrera que, na mudez de Janair, pudesse ter havido uma censura à minha vida[...]" (Idem).

A personagem-narradora é incomodada pela existência dessa mulher, que só conseguiu comunicar-se através de desenhos na parede do pequeno quarto em que habitava. A comunicação não houve pois, durante os seis meses que ali esteve a empregada, diz G.H.: "eu não me deixara ter" (Idem). Não houve comunicação, e o silêncio de Janair é interpretado como odioso (Idem), pois o que havia era indiferença 
(Idem, p. 41). G.H. a usou como "se ela não tivesse presença" (Idem).

Assim, a realidade do inesperado surge, invadindo a narrativa. A invasão pode ser como em G.H., de desenhos a carvão na parede, marcando a existência e a miséria de Janair. G.H. percebe no desenho a mensagem vinda de um ser, na visão focalizadora da narradora, desprivilegiado. Essa mensagem toca em G.H., deixando-a incomodada. Janair se presencia em G.H. por meio de tais inscrições. Toca e se presencia também no leitor, que percebe a existência terrível de Janair, e a relação insalubre estabelecida entre empregada e patroa, isso apesar da viagem metafísica proposta por G.H.. A partir desse ponto, G.H. será levada a vivenciar a realidade de Janair, G.H. é contaminada em seu próprio universo de proteção: ela vivia numa cobertura sofisticada, era escultura; Janair vivia num pequeno quarto, nessa cobertura.

No desenho de Janair, as figuras não olham umas para as outras, nas palavras de G.H.: "cada figura olhava para frente, como se nunca tivesse olhado para o lado, como se nunca tivesse visto a outra e não soubesse que ao lado existia alguém." (Idem, p. 39). Simbolicamente, Janair questiona G.H. e a relação "humana" estabelecida naquela cobertura luxuosa. $\mathrm{O}$ contato era tão ausente entre as duas mulheres que habitavam aquela casa que, diz G.H., "quis lembrar-me de seu rosto [de Janair], e admirada não consegui." (Idem, p. 40).

\section{No intestino do cão}

Diz Abel:

Não pretendo ser limpo: estou sujo e sufocado, nos intestinos de um cão. Angustia-me, claro, reconhecer que a sombra da opressão infiltra-se nas minhas armações e envenena-as. [...] Que salve, das tripas, o que pode ser salvo, mas com o seu cheiro de podridão. (LINS, 1995: 332)

Estas palavras de Abel ajudam-nos a entender a posição em que se encontram as obras analisadas. A opressão é ampla e, no Brasil, especificadamente, a opressão social é evidente. Nesse ponto é possível entender o imperativo presente nas palavras de Rodrigo, o escritor narrador de A hora da estrela. Como o escritor pode conviver tranquilamente com pessoas que não têm o mínimo para a sobrevivência? Abel, o narrador-escritor, discute isso em Avalovara; Osman Lins, em suas entrevistas, declara ser quase impossível ignorar o mundo à volta 
do escritor; ${ }^{5}$ Rodrigo abertamente se declara incomodado por Macabéa e impossibilitado de ignorar a existência da nordestina. Nesses casos, a discussão sobre a impossibilidade de imparcialidade é elevada a primeiro plano, exposta na superfície da obra. Ao mesmo tempo, algo que está sendo demonstrado, implicitamente, sobra, contamina o universo narrativo.

Em A paixão segundo G.H., a discussão nasce meio implícita. Para que G.H. desperte para a existência de Janair, é necessária uma auto-análise a partir do desenho na parede. A voz de Janair surge pela interpretação feita por G.H. de seu desenho quase rupestre. Apesar de considerar irrelevante para o entendimento da obra literária, é possível supor que o imperativo aqui mencionado também se impunha a Lispector, no sentido em que essas figuras terem nascido tão fortes em sua obra.

Nesse âmbito de análise, é possível afirmar que a literatura, nas obras em questão, existe sem ignorar a realidade desastrosa da sociedade brasileira, principalmente em relação ao abismo econômico entre ricos e pobres. A literatura é afetada em sua estrutura por essa realidade, já que os narradores-personagens discutem na própria obra tais problemas, de forma metaficcional. Nesse contexto, podemos retomar a última frase citada de Abel: "que salve, das tripas, o que pode ser salvo, mas com o seu cheiro de podridão." A literatura coexiste no Brasil com situações sociais terríveis. Apesar da realidade miserável da grande maioria dos brasileiros, a literatura não consegue, pelo menos nas obras analisadas, ser indiferente a tal realidade. $\mathrm{O}$ ponto focalizador dos narradores denunciam isso. A literatura se salva, mas com seu cheiro de podridão.

Retomando o início de meu texto, essas instâncias da realidade nacional não cabem no poema, no romance, na Carta de Caminha sem incômodo. Elas incomodam e estão ali presentes, com seus sussurros, como os de Janair; com seu silêncio, como o de Macabéa; ou como uma temática metaficcional a ser trabalhada por Abel, em Avalovara. É nesse sentido que entendo a citação de Guimarães Rosa que abre meu

${ }^{5}$ Osman Lins escreveu a maioria de suas obras em plena ditadura militar brasileira. Boa parte das angústias de Abel e mesmo de Lins dizem respeito a esse momento nacional. Ainda Lins, em A rainha dos cárceres da Grécia, trata de uma opressão parecida com a vivenciada por Macabéa: a opressão que recai sobre a desgraçada Maria da França, que tenta, e não consegue, se aposentar pelo INPS, órgão brasileiro de aposentadoria.

Faculdade de Letras | Universidade de Coimbra 
texto: um livro pode valer pelo que nele não deveu caber, porque pode estar ali sendo de(monstra)do.

É deste nível que busquei entender o arranjo dos romances mencionados: uma organização de ausência e presença, principalmente por parte das personagens-narradoras; uma organização que movimenta a obra em direção ao leitor, em direção à realidade que os circunda: tanto o leitor quanto a obra. Por causa desse jogo de presença e ausência, também incomodado, falei em algo que não cabe, mas que está ali presente, sobrando de alguma forma.

\section{O tumulto em nós}

Ainda, não é só a literatura que acaba se salvando contaminada. Aquele que busca pensar tal realidade encontra-se em situação análoga à dos narradores analisados. Estar pensando a literatura - num escritório, atrás de um computador, tomando café e comendo frutas nos intervalos (para lembrar Rodrigo, de $A$ hora da estrela), enquanto, atrás da janela acortinada, passeiam a fome, a miséria, pessoas sobrevivendo da cata de lixo, comendo lixo - é um luxo que expõe o pesquisador ao tremor do incômodo. Esta narrativa não está isenta deste incômodo, assim como os governantes da capital do Brasil não estão isentos das pessoas viventes das latas de lixo que coabitam com seus automóveis luxuosos. Não basta fechar as janelas dos carros, dar esmolas altíssimas perto do natal: deste incômodo não estamos isentos pois, pensando com Aristóteles, estas pessoas são semelhantes nossos e, como lembra Rodrigo (p. 54), nós poderíamos ter nascido elas. Só da possibilidade de sermos elas, estremecemos. 


\section{Bibliografia}

ARENDT, Hannah. A condição humana. Trad. Roberto Raposo. Rio de Janeiro: Forense Universitária, 1981.

ARISTÓTELES. La poética. (Ed. bilingüe: grego e espanhol) Trad. de D. Joseph Goya y Muniain. Madrid: De Órden Superior en la Imprenta de Don Nenito Cano, 1798.

______. A poética. Trad. de Eudoro de Sousa. Lisboa: Guimarães \& C. ${ }^{\text {a }}$ editores, 1951

BAL, Mieke. Narratology: introduction to the theory of narrative. Trad. de Christine van Boheemen, Toronto, 1997.

DALCASTAGNÈ, Regina. A garganta das coisas. Brasília: Editora Universidade de Brasília: São Paulo: Imprensa Oficial do Estado, 2000.

- O espaço da dor: o regime de 64 no romance brasileiro. Brasília: Editora da Universidade de Brasília, 1996.

FIOROTTI, Devair Antônio. A palavra encena: uma discussão da linguagem poética a partir de Manoel de Barros. (Tese de doutorado). Universidade de Brasília, UnB, 2006.

GULLAR, Ferrreira. Toda poesia: 1950-1980. São Paulo: Círculo do Livro, 1980.

JOYCE, James. A portrait of the artist as a young man. London: Penguin, 1996.

LINS, Osman. Avalovara. $5^{\text {a }}$ ed. São Paulo: Cia das Letras, 1995. . Evangelho na taba: outros problemas inculturais brasileiros. São Paulo: Summus, 1979.

LISPECTOR, Clarice. A hora da estrela. $25^{\text {a }}$ ed. Rio de Janeiro: Francisco Alves, 1997. 1998.

ROSA, Guimarães. Tutaméia: terceiras estórias. $3^{\mathrm{a}}$ ed. Rio de Janeiro: José Olympio, 1969.

SÓFOCLES. Tragédias: Édipo rey - Édipo en Colono. Texto bilíngüe grego/espanhol. Trad. de Ignácio Errandonea, S. I. V.I. 1959. 